\title{
Molecular Epidemiology of Metallo- $\beta$-lactamase Producing Pseudomonas aeruginosa Clinical Isolates
}

\section{Myungwon Choi*}

\section{Research Institute for Antimicrobial Resistance, Kosin University College of Medicine, Busan 602-703, Korea}

Received August 16, 2012 /Revised August 27, 2012 /Accepted August 29, 2012

\begin{abstract}
The emergence and dissemination of carbapenem-resistant bacteria have resulted in limitations of antibiotic treatment and potential outbreaks of metallo- $\beta$-lactamase (MBL) producing Pseudomonas aeruginosa resistant to carbapenems. In this study, we conducted molecular characterization of the MBL genes of the $\beta$-lactam drug-resistant $P$. aeruginosa and prepared basic data for treatment and prevention of proliferation of antimicrobial-resistant bacterial infections. Forty-two $P$. aeruginosa isolates of 254 were resistant to imipenem or meropenem. Among the 42 isolates, 28 isolates were positive for the Hodge test, and 23 isolates were positive for the EDTA-disk synergy test (EDST). MBLs were detected in 59.5\% (25/42) of $P$. aeruginosa isolates. Eight isolates harbored blamP-6, whereas 17 isolates harbored bla $\mathrm{IIM}_{\mathrm{IM}}$. The bla $a_{\mathrm{IMP}-6}$ gene was in a class 1 integron containing five gene cassettes: bla $a_{\mathrm{IMP}-6,}$ qac, aacA4, blaxxA-1, and aadA1. Some strains that produce IMP-6 and VIM-2 showed epidemiological relationships. The bla $a_{\mathrm{IMP}-6}$ gene in carbapenem-resistant $P$. aeruginosa showed an identical pattern to a gene cassette that was reported at a hospital in Daegu, Korea. Therefore, MBL-producing $P$. aeruginosa is already endemic in the community. We are concerned that the existence of carbapenem-resistant bacteria containing the bla infections. We believe that we should select appropriate antibiotics based on the antibiotic susceptibility test and continue the research to prohibit the emergence and spread of antibiotics resistant bacteria.
\end{abstract}

Key words : Metallo-beta-lactamase (MBL), Pseudomonas aeruginosa, blaviM-2, blam

\section{서 론}

Pseudomonas aeruginosa ( $P$. aeruginosa)는 호기성의 포도당 비발효 그람음성간균으로 주로 기회감염을 일으키며, 눈의 감 염, 외이도염, 골수염, 뇌수막염, 심내막염, 폐렴, 요로감염, 균 혈증 등 다양한 유형의 감염증을 유발한다[5]. 그리고 이 균은 세포외막에 특이적인 porin을 갖고 있고[16], 염색체성 $\beta$ -lactamase를 생성하여[11], 광범위 $\beta$-lactam 제제 일부를 포 함한 여러 항균제에 자연내성을 갖지만, ceftazidime, piperacillin, ticarcillin 등에는 감수성을 나타낸다. P. aeruginosa감 염에는 imipenem, meropenem, ertapenem 등 carbapenem 계 열의 항균제가 선택치료제로 사용되고 있지만, 이러한 약제에 대한 내성균도 나타나고 있으며, 그 내성의 기전은 세포외막 단백질의 변이, 염색체성 AmpC $\beta$-lactamase의 과량생성, carbapenem을 가수분해하는 $\beta$-lactamase의 생성(carbapenemase) 등이 있다. 이들 중 P. aeruginosa의 carbapenem에 대한 내성을 획득하는 가장 중요한 기전은 $\beta$-lactamase의 생성이며 $[2,4,23]$, carbapenem을 가수분해하는 $\beta$-lactamase의 유형으로는 활성

*Corresponding author Tel : +82-51-990-6420, Fax : +82-51-990-3081

E-mail : wmc0916@naver.com
중심에 serine기가 있는 serine $\beta$-lactamase (Ambler class A형 및 $\mathrm{D}$ 형 $\beta$-lactamase $)$ 와 활성 중심에 금속 2 가 이온 $\left(\mathrm{Zn}^{2+}\right.$ 등 $)$ 을 필요로 하는 metallo- $\beta$-lactamase $(\mathrm{MBL}, \mathrm{Ambler}$ class $\mathrm{B}$ 형 $\beta$ lactamase)로 나눌 수 있다.

그 중 Class B carbapenemase 효소는 penicillin, cephalosporin, carbapenem 등 monobactam을 제외한 $\beta$-lactam 항 균제 대부분에 가수분해 활성이 있고, clavulanic acid에 의해 억제되지 않으며, EDTA에 의해서 활성이 억제된다[13]. Class B carbapenemase인 IMP (active on imipenem)형은 1988년 일본에서 분리된 $P$. aeruginosa에서 처음 발견되었으며[17], 지 금까지 17 가지 이상의 변종이 보고되어 있고(http://www.lahey.org/Studies/) 국내에서는 IMP-1을 생성하는 P. aerugino$s a$ 와 Acinetobacter baumannii가 보고 된 바 있다[8]. 또한 VIM (Verona integron-encoded metallo- $\beta$-lactamase)형은 1999년 이태리의 P. aeruginosa에서 처음 검출되어 현재까지 11가지 이상의 변종이 보고 되었고(http:// www. lahey. org/Studies), 국내에서는 VIM-2를 생성하는 $P$. aeruginosa, $P$. putida, A baumannii, A. genomospecies, Serratia marcescens 및 Enterobacter cloacae가 보고 된 바 있다[8,21,22]. 최근에는 브라 질, 독일 및 한국에서 분리된 P. aeruginosa에서 새로운 유형의 MBL인 SPM-1, GIM-1 및 SIM-1이 각각 보고되었다[3,10,12]. 
또한 MBL 유전자는 integron에 존재하여 transposon 또는 plasmid를 이용하여 다른 균에 용이하게 전달될 수 있으며[8], integron은 재조합 효소(recombinase)를 생산하는 integrase 유전자(int1)의 염기서열에 따라 class 1-5로 구분하고, class $1,2,3$ 는 주로 그람 음성세균에서 발견되고 항균제 내성과 관련이 있으며, 그 중 class 1 integron이 주로 임상적 의미를 갖는 경우가 많고, class 4, 5는 Vibro species에서만 발견된다. Class 1 integron에는 $5^{\prime}$ 보존지역과 $3^{\prime}$ 보존지역이 있고 그 사이 가변영역(variable region)이 존재하는데 이 가변영역 내의 recombination site (attII) 유전자 위치에 내성관련 유전자 집단 인 gene cassette가 삽입됨으로써 그람음성 세균의 항균제 내 성에 관여하게 되고 IMP, VIM 및 GIM 유전자는 대부분 class 1 integron안에 gene cassette로 존재한다.

따라서 integron의 분포와 특징에 대한 연구는 그람 음성 세균에서의 항균제 내성 출현과 전파를 추적하는데 있어 매우 중요한 역할을 하므로 본 연구에서는 항균제 내성의 분포와 변화, integron의 유전학적 특징을 살펴보고자 하였다. 그리고 현재까지 MBL 획득에 관여하는 것으로 알려진 기전은 plasmid, integron, transposon, insertion sequence common region이 있는데 이들은 동시에 많은 내성유전자를 운반할 수 있으므로 carbapenem 내성 세균의 출현 및 확산은 carbapenem계 항균제를 포함한 대부분의 $\beta$-lactam항균제에 대한 활 성을 낮추어 감염증 치료시 선택압을 가중시킬 수 있다. 이에 본 연구에서는 부산에 있는 고신대학교 복음병원에서 분리된 carbapenem계 항균제 내성 P. aeruginosa를 대상으로 MBL 유 전형을 규명함으로써 내성세균의 감염증 치료지침 및 확산방 지책 마련에 기초 자료를 제공하고자 하였다.

\section{재료 및 방법}

\section{균주의 수집}

부산의 고신대학교 복음병원에서 2008년 한 해 동안 254 개의 임상 검체에서 P. aeruginosa를 42주 분리 동정하였으 며, 균주의 동정은 전통적인 생화학적 방법과 Vitek GNI card (bioMerierux Vitek Inc, Hazelwood, MO, USA)로 확 인하였다.

\section{Carbapenemase 생성균주 선별과 MBL 생성 선별시험}

Hodge 변법으로 carbapenemase 생성균주를 선별하였으 며[15], 시험의 정확성을 위해 참조균주인 Escherichia coli ATCC 25922의 감수성을 동시에 시험하였다. 또한 Lee 등[7] 의 방법에 따라서 EDTA에 sodium mercaptoacetic acid (SMA)를 첨가한 disk로 synergy 시험하여 선별하였다. 세균 이 접종된 배지는 $37^{\circ} \mathrm{C}$ 항온기에 18 시간 배양 후, 두 디스크 사이에서 상승효과에 의한 억제대의 확장현상이 관찰되면 양 성으로 판정하였다.
항균제 감수성 시험과 최소억제농도(minimum inhibitory concentration, $\mathrm{MIC}$ ) 측정

Clinical and Laboratory Standards Institute (CLSI) 디스크 확산법으로 시험하였고[5], 항균제 디스크로는 ceftazidime, meropenem, imipenem, colistin, gentamicin, amikacin, tobramycin 및 ciprofloxacin 디스크(BBL, Cockeysville, MD, USA)를 사용하였다. 또한 CLSI 한천희석법으로 meropenem (유한, 서울)과 imipenem (중외, 화성)에 대한 $\mathrm{MIC}$ 를 측정하 였으며[18], $37^{\circ} \mathrm{C}$ 호기성 환경에서 18 시간 배양 후 항균제 농도 에 따른 집락의 증식 양상을 관찰하였다. 참조균주인 E. coli ATCC 25922의 감수성 시험도 동시에 시행하였다.

\section{접합에 의한 내성 전달}

Broth mating법으로 시험하였다[1]. Azide에 내성인 $P$. aeruginosa PAO 4089를 내성 수여자로 사용하며, 내성 공여 자와 수여자를 각각 Brain heart infusion (Difco, Detroit, MI, USA) 액체배지에 접종하여서 3시간 진탕배양 하였다. 공여 자 배양액 $0.2 \mathrm{ml}$ 와 수여자 배양액 $2.2 \mathrm{ml}$ 를 시험관에 넣어 서 $37^{\circ} \mathrm{C}$ 에서 1 시간 배양 후, imipenem $8 \mathrm{mg} / \mathrm{l}$, rifampin 100 $\mathrm{mg} / 1$ 가 함유된 MacConkey 한천(Difco, Detroit, MI, USA) 에 접종하였다. $37^{\circ} \mathrm{C}$ 에서 18 시간 배양 후 피전달 접합균주를 선별하였고, 피전달 접합균주가 생겼을 경우 내성유전자의 전달을 확인하기 위하여 PCR (polymerase chain reaction)을 시행하였다.

\section{분자유전학적 방법에 의한 $\beta$-lactamase 유전형 시험}

B-lactamase 유전형인 bla gene은 PCR로 염기서열을 분석 하여 내성유전자의 유전형을 조사하였다. 염기서열의 상동성 에 따라서 17 가지 이상의 변종이 보고 된 IMP형은 IMP-1, -2, $-4,-11,-18$, 및 - 19인 6 set primers를 사용하였고, 11가지 이상의 변종이 보고된 VIM형은 VIM-1, -2의 2 set primers를 사용하였으며, 아형이 보고되지 않은 GIM-1, SPM-1 및 SIM-1 은 각 1 쌍의 primer를 사용하였다(Table 1). 유전자의 염기서 열은 GenBank의 염기서열 정보를 참고하였으며, DNA Space version 3.02 (Genetic System, Hitachi, Japan)와 Vector NTI Suite (InforMax, Frederick, MD, USA)를 사용한 multiple alignment 분석 결과에 기초하여 $\beta$-lactamase 유전자의 특이 적인 부분을 primer로 고안하였다. 고안된 primer와 ESBL (extended-spectrum-ß-lactamase) 유전자의 염기서열 동정은 BLAST로 분석하였다. DNA 추출액으로 premix를 만들어 Gene Amp PCR System 9600 (Perkin-Elmer Centus Corp., Norwalk, CT, USA)으로 PCR을 시행하였다. 전기영동 하여 band 확인한 후 Sequenase Version 2.0 DNA sequencing kit (U.S. Biochemicals, Cleveland, OH, USA)를 이용하여 dideoxy-mediated chain termination 법으로 양방향으로 염기 서열을 분석하였다[15]. 
Table 1. Primer information for the PCR and sequencing

\begin{tabular}{|c|c|c|c|c|}
\hline Names & Nucleotide Sequences $\left(5^{\prime} \rightarrow 3^{\prime}\right)$ & Product size (bp) & Accession No. & Target genes \\
\hline $\begin{array}{l}\text { IMP-1F } \\
\text { IMP-1R }\end{array}$ & $\begin{array}{l}\text { GCT ACC GCA GCA GAG TCT TTG } \\
\text { CCT TTA ACC GCC TGC TCT AAT G }\end{array}$ & 656 & S71932 & IMP-1, -3, -6, -10 \\
\hline $\begin{array}{l}\text { IMP-2F } \\
\text { IMP-2R }\end{array}$ & $\begin{array}{l}\text { ATG TTA CGC AGC AGG GCA G } \\
\text { ATG CTC AGT CAT GAG GCG C }\end{array}$ & 938/991 & AJ243491 & IMP-2, -8, -10, -12, -13 \\
\hline $\begin{array}{l}\text { IMP-4F } \\
\text { IMP-4R }\end{array}$ & $\begin{array}{l}\text { GAA GGC GTT TAT GTT CAT ACT TCG } \\
\text { GCG TCA CCC AAA TTA CCT AGA CC }\end{array}$ & 473 & AF244145 & IMP-4, $-5,-7,-9$ \\
\hline $\begin{array}{l}\text { IMP-11F } \\
\text { IMP-11R }\end{array}$ & $\begin{array}{l}\text { GAG AAG CTT GAA GAC GGT GTT TAT } \\
\text { AGG TAG CCA AAC CAC TAC GTT ATC }\end{array}$ & 420 & AB074436 & IMP-11, -12, -21 \\
\hline $\begin{array}{l}\text { IMP-18F } \\
\text { IMP-18R }\end{array}$ & $\begin{array}{l}\text { CAT TGC TGC TGC AGA TGA TTC } \\
\text { CTG CAA GAG TGA TGC GTT TG }\end{array}$ & 634 & AY780674 & IMP-18 \\
\hline $\begin{array}{l}\text { IMP-19F } \\
\text { IMP-19R }\end{array}$ & $\begin{array}{l}\text { GTT TTA AGT GTA TGA TTC CTT TGT AGT } \\
\text { CAG CCT GTT CCC ATG TAC G }\end{array}$ & 679 & AB201265 & IMP-19, -20 \\
\hline $\begin{array}{l}\text { VIM-1F } \\
\text { VIM-1R }\end{array}$ & $\begin{array}{l}\text { GTT TGG TCG CAT ATC GCA AC } \\
\text { AGA CCG CCC GGT AGA CC }\end{array}$ & 581 & Y18050 & VIM-1, $-4,-5,-7,-11$ \\
\hline $\begin{array}{l}\text { VIM-2F } \\
\text { VIM-2R }\end{array}$ & $\begin{array}{l}\text { GTT TGG TCG CAT ATC GCA AC } \\
\text { CTA CTC AAC GAC TGA GCG ATT TGT }\end{array}$ & 645 & AF191564 & VIM-2, $-3,-6,-8,-9,-10$ \\
\hline $\begin{array}{l}\text { GIM-1F } \\
\text { GIM-1R }\end{array}$ & $\begin{array}{l}\text { CAG GGT CAT AAA CCG CTA GAA G } \\
\text { AAC TTC CAA CTT TGC CAT GC }\end{array}$ & 613 & AJ620678 & GIM-type \\
\hline $\begin{array}{l}\text { SPM-1F } \\
\text { SPM-1R }\end{array}$ & $\begin{array}{l}\text { GAG AGC CCT GCT TGG ATT C } \\
\text { GCG ACC TTG ATC GTC TTG TT }\end{array}$ & 783 & AY341249 & SPM-type \\
\hline $\begin{array}{l}\text { SIM-1F } \\
\text { SIM-1R }\end{array}$ & $\begin{array}{l}\text { GCA CTT TAA ATA CCG CGT TTG } \\
\text { TAA TTA ATG AGC GGC GGT TT }\end{array}$ & 709 & AY887066 & SIM-type \\
\hline
\end{tabular}

blamp-6가 포함된 integron의 유전자 환경

IMP (active on imipenem)형 MBL 생성 유전자인 blalMP-6 유전자는 imipenem에 강한 활성을 나타내며, 처음 발견된 IMP-1 유전자의 196번 serine이 glycine으로 치환된 것으로 bla 1 MP-6 유전자가 포함된 integron과 이 유전자가 포함되지 않 은 integron을 구분하여 class 1 integron의 5'-CS (conserved sequence), 3'-CS 및 유전자 cassette primer로 PCR 하였으며,
증폭된 $\mathrm{PCR}$ 산물의 DNA 염기서열을 분석하여 class $1 \mathrm{in}-$ tegron의 구조를 확인하였다(Table 2).

Enterobacterial repetitive intergenic consensus
(ERIC)- based PCR
다양한 균주들의 분자생물학적 동정에 응용되는 ERIC
PCR은 증폭된 크기가 다른 DNA 단편들을 이용하여 각 세

Table 2. Sequence of the PCR primers used for class 1 integron study

\begin{tabular}{|c|c|c|}
\hline Names & Targets & Sequences $\left(5^{\prime} \rightarrow 3^{\prime}\right)$ \\
\hline INTI-F & \multirow{3}{*}{ IntI gene } & CCA AGC TCT CGG GTA ACA TC \\
\hline INTI-R & & CAT GAA AAC CGC CAC TGC \\
\hline $5^{\prime} \mathrm{CS}-\mathrm{mF}$ & & CTT AAG GAG GCT ACG GCT TTC \\
\hline qacE $\Delta 1-\mathrm{F}$ & \multirow{3}{*}{ qacE $\Delta 1$ gene } & GAA AGG CTG GCT TTT TCT TG \\
\hline qacE $\Delta 1-R$ & & GCA GCG ACT TCC ACG ATG \\
\hline $3^{\prime} \mathrm{CS}-\mathrm{mR}$ & & TGT GAA AGG CGA GAT CAT CA \\
\hline sul1-F & \multirow{3}{*}{ sul1 gene } & TCA CCG AGG ACT CCT TCT TC \\
\hline sul1-R & & GGG TTT CCG AGA AGG TGA TT \\
\hline sul1-mF & & ACG AGA TTG TGC GGT TCT TC \\
\hline qac-F & \multirow{2}{*}{ qac gene } & CAA TCT TTG GCG AGG TCA TC \\
\hline qac-R & & CGC TGA CCT TGG ATA GCA G \\
\hline aadA1-mF & \multirow{2}{*}{ aadA1 gene } & ACA TCA TTC CGT GGC GTT AT \\
\hline aadA1-mR & & AGG TTT CAT TTA GCG CCT CA \\
\hline aacA4-F & \multirow{2}{*}{ aacA4 gene } & TGA CCT TGC GAT GCT CTA TG \\
\hline aacA4-R & & GAT GGA AGG GTT AGG CAA CA \\
\hline OXA1-F & \multirow{2}{*}{ blaoxA-1 gene } & TAT CTA CAG CAG CGC CAG TG \\
\hline OXA1-R & & TGC ACC AGT TTT CCC ATA CA \\
\hline
\end{tabular}


Table 3. Antimicrobial susceptibilities of MBL-producing $P$. aeruginosa isolates

\begin{tabular}{|c|c|c|c|c|c|c|c|c|}
\hline \multirow{2}{*}{ No.(42) } & \multicolumn{8}{|c|}{ antimicrobial susceptibilities $(\mathrm{mm})$} \\
\hline & CAZ & IPM & MEM & $\mathrm{CL}$ & GM & AN & $\mathrm{NN}$ & $\mathrm{CIP}$ \\
\hline 08PAE 1 & $19 \mathrm{~S}$ & $8 \mathrm{R}$ & $6 \mathrm{R}$ & $15 \mathrm{~S}$ & $15 \mathrm{~S}$ & $14 \mathrm{R}$ & $16 \mathrm{~S}$ & $15 \mathrm{R}$ \\
\hline 08PAE 2 & $6 \mathrm{R}$ & $9 \mathrm{R}$ & $6 \mathrm{R}$ & $14 \mathrm{~S}$ & $18 \mathrm{~S}$ & $17 \mathrm{~S}$ & $21 \mathrm{~S}$ & $17 \mathrm{I}$ \\
\hline 08PAE 4 & $22 \mathrm{~S}$ & $12 \mathrm{R}$ & $9 \mathrm{R}$ & $14 \mathrm{~S}$ & $17 \mathrm{~S}$ & $20 \mathrm{~S}$ & $22 \mathrm{~S}$ & $6 \mathrm{R}$ \\
\hline 08PAE 5 & $6 \mathrm{R}$ & $7 \mathrm{R}$ & $6 \mathrm{R}$ & $13 \mathrm{~S}$ & $6 \mathrm{R}$ & $6 \mathrm{R}$ & $6 \mathrm{R}$ & $6 \mathrm{R}$ \\
\hline 08PAE 7 & $21 \mathrm{~S}$ & $12 \mathrm{R}$ & $17 \mathrm{~S}$ & $12 \mathrm{~S}$ & $16 \mathrm{~S}$ & $18 \mathrm{~S}$ & $18 \mathrm{~S}$ & $24 \mathrm{~S}$ \\
\hline 08PAE 8 & $20 \mathrm{~S}$ & $11 \mathrm{R}$ & $8 \mathrm{R}$ & $13 \mathrm{~S}$ & $18 \mathrm{~S}$ & $22 \mathrm{~S}$ & $22 \mathrm{~S}$ & $27 \mathrm{~s}$ \\
\hline 08PAE 9 & $24 \mathrm{~S}$ & $15 \mathrm{I}$ & $12 \mathrm{R}$ & $13 \mathrm{~S}$ & $21 \mathrm{~S}$ & $24 \mathrm{~S}$ & $24 \mathrm{~S}$ & $27 \mathrm{~s}$ \\
\hline 08PAE 10 & $14 \mathrm{R}$ & $10 \mathrm{R}$ & $10 \mathrm{R}$ & $13 \mathrm{~S}$ & $23 \mathrm{~S}$ & $25 \mathrm{~S}$ & $26 \mathrm{~S}$ & $32 \mathrm{~s}$ \\
\hline 08PAE 11 & $6 \mathrm{R}$ & $9 \mathrm{R}$ & $6 \mathrm{R}$ & $13 \mathrm{~S}$ & $6 \mathrm{R}$ & $17 \mathrm{~S}$ & $7 \mathrm{R}$ & $7 \mathrm{R}$ \\
\hline 08PAE 13 & $19 \mathrm{~S}$ & $10 \mathrm{R}$ & $9 \mathrm{R}$ & $12 \mathrm{~S}$ & $6 \mathrm{R}$ & $6 \mathrm{R}$ & $6 \mathrm{R}$ & $6 \mathrm{R}$ \\
\hline 08PAE 15 & $8 \mathrm{R}$ & $14 \mathrm{I}$ & $7 \mathrm{R}$ & $11 \mathrm{~S}$ & $6 \mathrm{R}$ & $6 \mathrm{R}$ & $6 \mathrm{R}$ & $6 \mathrm{R}$ \\
\hline 08PAE 16 & $12 \mathrm{R}$ & $11 \mathrm{R}$ & $7 \mathrm{R}$ & $15 \mathrm{~S}$ & $8 \mathrm{R}$ & $8 \mathrm{R}$ & $6 \mathrm{R}$ & $6 \mathrm{R}$ \\
\hline 08PAE 17 & $6 \mathrm{R}$ & $11 \mathrm{R}$ & $6 \mathrm{R}$ & $12 \mathrm{~S}$ & $6 \mathrm{R}$ & $6 \mathrm{R}$ & $6 \mathrm{R}$ & $6 \mathrm{R}$ \\
\hline 08PAE 18 & $6 \mathrm{R}$ & $6 \mathrm{R}$ & $6 \mathrm{R}$ & $12 \mathrm{~S}$ & $6 \mathrm{R}$ & $9 \mathrm{R}$ & $6 \mathrm{R}$ & $17 \mathrm{I}$ \\
\hline 08PAE 19 & $7 \mathrm{R}$ & $11 \mathrm{R}$ & $6 \mathrm{R}$ & $13 \mathrm{~S}$ & $12 \mathrm{R}$ & $12 \mathrm{R}$ & $9 \mathrm{R}$ & $6 \mathrm{R}$ \\
\hline 08PAE 20 & $6 \mathrm{R}$ & $6 \mathrm{R}$ & $6 \mathrm{R}$ & $14 \mathrm{~S}$ & $15 \mathrm{~S}$ & $20 \mathrm{~S}$ & $14 \mathrm{I}$ & $20 \mathrm{I}$ \\
\hline 08PAE 22 & $10 \mathrm{R}$ & $6 \mathrm{R}$ & $6 \mathrm{R}$ & $15 \mathrm{~S}$ & $6 \mathrm{R}$ & $6 \mathrm{R}$ & $6 \mathrm{R}$ & $6 \mathrm{R}$ \\
\hline 08PAE 24 & $25 \mathrm{~S}$ & $13 \mathrm{R}$ & $11 \mathrm{R}$ & $14 \mathrm{~S}$ & $6 \mathrm{R}$ & $6 \mathrm{R}$ & $6 \mathrm{R}$ & $6 \mathrm{R}$ \\
\hline 08PAE 25 & $6 \mathrm{R}$ & $6 \mathrm{R}$ & $6 \mathrm{R}$ & $15 \mathrm{~S}$ & $6 \mathrm{R}$ & $6 \mathrm{R}$ & $6 \mathrm{R}$ & $6 \mathrm{R}$ \\
\hline 08PAE 26 & $7 \mathrm{R}$ & $11 \mathrm{R}$ & $6 \mathrm{R}$ & $15 \mathrm{~S}$ & $6 \mathrm{R}$ & $6 \mathrm{R}$ & $6 \mathrm{R}$ & $6 \mathrm{R}$ \\
\hline 08PAE 27 & $6 \mathrm{R}$ & $12 \mathrm{R}$ & $6 \mathrm{R}$ & $14 \mathrm{~S}$ & $6 \mathrm{R}$ & $6 \mathrm{R}$ & $6 \mathrm{R}$ & $6 \mathrm{R}$ \\
\hline 08PAE 28 & $6 \mathrm{R}$ & $14 \mathrm{I}$ & $6 \mathrm{R}$ & $14 \mathrm{~S}$ & $6 \mathrm{R}$ & $6 \mathrm{R}$ & $6 \mathrm{R}$ & $6 \mathrm{R}$ \\
\hline 08PAE 29 & $6 \mathrm{R}$ & $6 \mathrm{R}$ & $6 \mathrm{R}$ & $15 \mathrm{~S}$ & $6 \mathrm{R}$ & $6 \mathrm{R}$ & $6 \mathrm{R}$ & $6 \mathrm{R}$ \\
\hline 08PAE 30 & $22 \mathrm{~S}$ & $14 \mathrm{I}$ & $30 \mathrm{~S}$ & $14 \mathrm{~S}$ & $6 \mathrm{R}$ & $22 \mathrm{~S}$ & $7 \mathrm{R}$ & $28 \mathrm{~S}$ \\
\hline 08PAE 31 & $6 \mathrm{R}$ & $10 \mathrm{R}$ & $6 \mathrm{R}$ & $14 \mathrm{~S}$ & $6 \mathrm{R}$ & $6 \mathrm{R}$ & $6 \mathrm{R}$ & $6 \mathrm{R}$ \\
\hline 08PAE 32 & $16 \mathrm{I}$ & $6 \mathrm{R}$ & $6 \mathrm{R}$ & $16 \mathrm{~S}$ & $6 \mathrm{R}$ & $22 \mathrm{~S}$ & $23 \mathrm{~S}$ & $6 \mathrm{R}$ \\
\hline 08PAE 33 & $9 \mathrm{R}$ & $11 \mathrm{R}$ & $11 \mathrm{R}$ & $14 \mathrm{~S}$ & $21 \mathrm{~S}$ & $24 \mathrm{~S}$ & $24 \mathrm{~S}$ & $29 \mathrm{~S}$ \\
\hline 08PAE 34 & $10 \mathrm{R}$ & $6 \mathrm{R}$ & $6 \mathrm{R}$ & $14 \mathrm{~S}$ & $6 \mathrm{R}$ & $6 \mathrm{R}$ & $6 \mathrm{R}$ & $6 \mathrm{R}$ \\
\hline 08PAE 36 & $7 \mathrm{R}$ & $6 \mathrm{R}$ & $6 \mathrm{R}$ & $14 \mathrm{~S}$ & $6 \mathrm{R}$ & $6 \mathrm{R}$ & $6 \mathrm{R}$ & $6 \mathrm{R}$ \\
\hline 08PAE 38 & $6 \mathrm{R}$ & $6 \mathrm{R}$ & $6 \mathrm{R}$ & $15 \mathrm{~S}$ & $15 \mathrm{~S}$ & $20 \mathrm{~S}$ & $14 \mathrm{I}$ & $24 \mathrm{~S}$ \\
\hline 08PAE 39 & $10 \mathrm{R}$ & $17 \mathrm{~S}$ & $11 \mathrm{R}$ & $13 \mathrm{~S}$ & $7 \mathrm{R}$ & $7 \mathrm{R}$ & $7 \mathrm{R}$ & $7 \mathrm{R}$ \\
\hline 08PAE 40 & $22 \mathrm{~S}$ & $13 \mathrm{R}$ & $12 \mathrm{R}$ & $13 \mathrm{~S}$ & $20 \mathrm{~S}$ & $24 \mathrm{~S}$ & $24 \mathrm{~S}$ & $10 \mathrm{R}$ \\
\hline 08PAE 41 & $6 \mathrm{R}$ & $9 \mathrm{R}$ & $6 \mathrm{R}$ & $12 \mathrm{~S}$ & $6 \mathrm{R}$ & $6 \mathrm{R}$ & $6 \mathrm{R}$ & $6 \mathrm{R}$ \\
\hline 08PAE 42 & $9 \mathrm{R}$ & $6 \mathrm{R}$ & $6 \mathrm{R}$ & $13 \mathrm{~S}$ & $6 \mathrm{R}$ & $6 \mathrm{R}$ & $6 \mathrm{R}$ & $6 \mathrm{R}$ \\
\hline 08PAE 43 & $6 \mathrm{R}$ & $6 \mathrm{R}$ & $6 \mathrm{R}$ & $13 \mathrm{~S}$ & $6 \mathrm{R}$ & $6 \mathrm{R}$ & $6 \mathrm{R}$ & $6 \mathrm{R}$ \\
\hline 08PAE 45 & $19 \mathrm{~S}$ & $10 \mathrm{R}$ & $9 \mathrm{R}$ & $11 \mathrm{~S}$ & $18 \mathrm{~S}$ & $21 \mathrm{~S}$ & $20 \mathrm{~S}$ & $6 \mathrm{R}$ \\
\hline 08PAE 48 & $6 \mathrm{R}$ & $6 \mathrm{R}$ & $6 \mathrm{R}$ & $13 \mathrm{~S}$ & $6 \mathrm{R}$ & $6 \mathrm{R}$ & $6 \mathrm{R}$ & $6 \mathrm{R}$ \\
\hline 08PAE 49 & $11 \mathrm{R}$ & $6 \mathrm{R}$ & $6 \mathrm{R}$ & $15 \mathrm{~S}$ & $6 \mathrm{R}$ & $15 \mathrm{I}$ & $18 \mathrm{~S}$ & $6 \mathrm{R}$ \\
\hline 08PAE 50 & $11 \mathrm{R}$ & $6 \mathrm{R}$ & $6 \mathrm{R}$ & $13 \mathrm{~S}$ & $6 \mathrm{R}$ & $6 \mathrm{R}$ & $6 \mathrm{R}$ & $6 \mathrm{R}$ \\
\hline 08PAE 51 & $21 \mathrm{~S}$ & $11 \mathrm{R}$ & $7 \mathrm{R}$ & $12 \mathrm{~S}$ & $17 \mathrm{~S}$ & $20 \mathrm{~S}$ & $20 \mathrm{~S}$ & $21 \mathrm{~S}$ \\
\hline 08PAE 52 & $7 \mathrm{R}$ & $6 \mathrm{R}$ & $6 \mathrm{R}$ & $14 \mathrm{~S}$ & $14 \mathrm{I}$ & $20 \mathrm{~S}$ & $14 \mathrm{I}$ & $24 \mathrm{~S}$ \\
\hline 08PAE 53 & $6 \mathrm{R}$ & $6 \mathrm{R}$ & $6 \mathrm{R}$ & $15 \mathrm{~S}$ & $6 \mathrm{R}$ & $6 \mathrm{R}$ & $6 \mathrm{R}$ & $6 \mathrm{R}$ \\
\hline
\end{tabular}

Abbreviations: CAZ (ceftazidime), IPM (imipenem), MEM (meropenem), CL (colistin), GM (gentamicin), AN (amikacin),

$\mathrm{NN}$ (tobramycin), CIP (ciprofloxacin), R (resistance), I (intermediate), S (sensitive)

균 균주마다 고유한 DNA fingerprinting pattern이 결정되 고, 그 pattern들을 서로 비교하여 검체 균주간의 상보성과 유전학적 연관성 등을 결정하는 방법인데, 본 연구에서는 MBL생성 세균을 대상으로 ERIC PCR하여 내성유전자를 보 유한 세균의 역학적 연관성을 조사하였다. primer sequence
는 ERIC 1 (5'-GTG AAT CCC CAG GAG CTT ACA T-3') 을 사용하였다. ERIC PCR의 결과 분석은 band의 강도와 상 관없이 band의 분자량과 개수로 각 균주를 비교하며, 두 개 이상의 band 차이가 있으면 역학적 상관관계가 없는 것으 로 판단하였다[6]. 


\section{결 과}

\section{항균제 감수성 검사}

2008년 1월부터 9월까지 부산의 고신대학교 복음병원의 254개 임상 검체에서 42 개의 $P$. aeruginosa 균주를 분리하였다. 이들 균주에 대한 $\beta$-lactam계 항균제인 Carbapenem계의 내 성률(R)은 meropenem이 95.2\% (40/42주), imipenem은 88.1\% (37/42)로 높게 나타났으며, Cephalosporins계인 ceftazidime도 $71.4 \%$ (30/42주)의 내성률을 나타냈다. 비ß-lactam 계 항균제로는 gentamicin $66.7 \%$ (28/42주), tobramycin $61.9 \%$ (26/42주), amikacin 59.5\% (25/42주)으로 나타났으며, colistin에 대한 내성은 없었다(Table 3).

\section{Carbapenemase 및 MBL 생성균주 선별}

P. aeruginosa 42주중에서 28주가 Carbapenemase 생성균주 를 선별하는 Hodge 변법에서 양성반응을 보였고, MBL 생성 균주를 선별하는 방법으로는 EDTA-disk synergy test (EDST)

Table 4. EDTA-disk synergy test (EDST) and Hodge test of MBL-producing $P$. aeruginosa isolates

\begin{tabular}{|c|c|c|}
\hline No. & Disk synergy (23) & Hodge test (28) \\
\hline 08PAE 1 & IPM & $\mathrm{O}$ \\
\hline 08PAE 5 & IPM & $\mathrm{O}$ \\
\hline 08PAE 8 & IPM & $\mathrm{O}$ \\
\hline 08PAE 9 & MEM & $\mathrm{O}$ \\
\hline 08PAE 11 & IPM & $\mathrm{O}$ \\
\hline 08PAE 17 & - & $\mathrm{O}$ \\
\hline 08PAE 18 & - & $\mathrm{O}$ \\
\hline 08PAE 20 & MEM & $\mathrm{O}$ \\
\hline 08PAE 22 & IPM & $\mathrm{O}$ \\
\hline 08PAE 25 & - & $\mathrm{O}$ \\
\hline 08PAE 26 & IPM & $\mathrm{O}$ \\
\hline 08PAE 27 & IPM & $\mathrm{O}$ \\
\hline 08PAE 28 & IPM & $\mathrm{O}$ \\
\hline 08PAE 29 & - & $\mathrm{O}$ \\
\hline 08PAE 31 & IPM & $\mathrm{O}$ \\
\hline 08PAE 32 & IPM & $\mathrm{O}$ \\
\hline 08PAE 34 & IPM & $\mathrm{O}$ \\
\hline 08PAE 36 & - & $\mathrm{O}$ \\
\hline 08PAE 38 & IPM & $\mathrm{O}$ \\
\hline 08PAE 41 & IPM & $\mathrm{O}$ \\
\hline 08PAE 42 & IPM & $\mathrm{O}$ \\
\hline 08PAE 43 & IPM & $\mathrm{O}$ \\
\hline 08PAE 48 & IPM & $\mathrm{O}$ \\
\hline 08PAE 49 & IPM & $\mathrm{O}$ \\
\hline 08PAE 50 & IPM & $\mathrm{O}$ \\
\hline 08PAE 51 & IPM & $\mathrm{O}$ \\
\hline 08PAE 52 & IPM MEM & $\mathrm{O}$ \\
\hline 08PAE 53 & IPM & $\mathrm{O}$ \\
\hline
\end{tabular}

Abbreviations: IPM (imipenem), MEM (meropenem)
결과 23주가 Imipenem 혹은 meropenem에서 양성반응을 나 타냈다(Table 4).

\section{$\mathrm{MBL}$ 유전형 확인 및 접합}

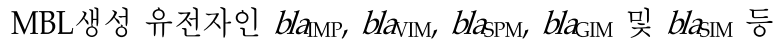
의 유전자 검출을 위한 PCR에서 blaMP 유전자에 8주가 양성반 응을 보였고, blaxiM 유전자에 17주가 양성반응을 보여 전체 균주 가운데 59.5\% (25/42)가 MBL을 생성하였다. DNA의 염 기서열 분석결과는 blamp 유전자에 양성반응을 보인 8 주 모두 bla $a_{\mathrm{MP}-6}$ 유전자(GenBank accession no. EU117233)이었고, blavIM 유전자에 양성반응을 보인 17주 모두는 blavIM-2 유전자 (GenBank accession no. AF191564)로 확인이 되었다(Table 5). 접합에 의한 내성유전자 전달 시험은 $\mathrm{PCR}$ 로 확인한 결과 band가 관찰되지 않아 $\mathrm{MBL}$ 생성 유전자가 수여균인 $P$. aeruginosa PAO4089에 전달되지 않은 것으로 나타났다.

\section{$\mathrm{MBL}$ 생성 $P$. aeruginosa의 특성}

blaMp-6 유전자를 지닌 $P$. aeruginosa 8 주에 대한 imipenem 의 $\mathrm{MIC}$ 범위는 $8-32 \mathrm{\mu g} / \mathrm{ml}$ 이었고, meropenem의 $\mathrm{MIC}$ 는

Table 5. Genotypes and MIC of MBL-producing $P$. aeruginosa isolates

\begin{tabular}{cccc}
\hline \multirow{2}{*}{ No. } & \multirow{2}{*}{ genotypes } & \multicolumn{2}{c}{ MIC $(\mu \mathrm{g} / \mathrm{ml})$} \\
\cline { 3 - 4 } 08PAE 1 & VIM-2 & 64 & MEM \\
08PAE 5 & IMP-6 & 16 & $>256$ \\
08PAE 11 & IMP-6 & 32 & $>256$ \\
08PAE 17 & IMP-6 & 32 & $>256$ \\
08PAE 18 & VIM-2 & 128 & 128 \\
08PAE 20 & VIM-2 & 128 & 128 \\
08PAE 22 & VIM-2 & 128 & 128 \\
08PAE 25 & VIM-2 & 64 & 128 \\
08PAE 26 & IMP-6 & 32 & $>256$ \\
08PAE 27 & IMP-6 & 32 & $>256$ \\
08PAE 28 & IMP-6 & 8 & $>256$ \\
08PAE 29 & VIM-2 & 64 & 64 \\
08PAE 31 & IMP-6 & 16 & $>256$ \\
08PAE 32 & VIM-2 & 32 & 64 \\
08PAE 34 & VIM-2 & 64 & 64 \\
08PAE 36 & VIM-2 & 64 & 64 \\
08PAE 38 & VIM-2 & 64 & 64 \\
08PAE 41 & IMP-6 & 16 & $>256$ \\
08PAE 42 & VIM-2 & 32 & 64 \\
08PAE 43 & VIM-2 & 64 & 64 \\
08PAE 48 & VIM-2 & 64 & 32 \\
08PAE 49 & VIM-2 & 64 & 64 \\
08PAE 50 & VIM-2 & 64 & 64 \\
08PAE 52 & VIM-2 & 64 & 128 \\
08PAE 53 & VIM-2 & 64 & 128 \\
\hline Abbreviations: IPM (imipenem), MEM (meropenem)
\end{tabular}




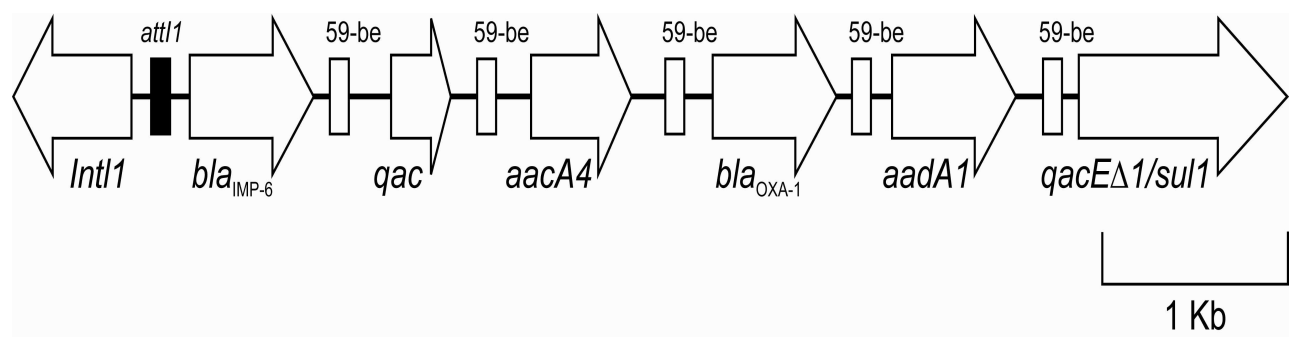

Fig. 1. Schematic map of the class 1 integron carrying the blamp-6 gene cassette. White bricks, 59-base elements (59-be); black brick, the recombination site attI1.

$>256 \mu \mathrm{g} / \mathrm{ml}$ 이었다. bla긱-2 유전자를 지닌 P. aeruginosa 17 주 의 imipenem과 meropenem의 MIC 범위는 모두 32-128 $\mathrm{\mu g} /$ $\mathrm{ml}$ 이었으며 이 두 항균제의 $\mathrm{MIC}_{50}$ 과 $\mathrm{MIC}_{90}$ 은 각각 $64 \mu \mathrm{g} / \mathrm{ml}$ 와 $128 \mu \mathrm{g} / \mathrm{ml}$ 으로 확인되었다(Table 5).

\section{blamp-6가 포함된 integron의 구조}

$5^{\prime} \mathrm{CS}-\mathrm{mF}$ 와 3'CS-mR를 이용한 PCR에서 5'-CS 및 3'-CS 보 존지역을 지닌 전형적인 class 1 integron이 검출되었다. Class 1 integron의 5'-CS 보존지역은 integrase 유전자(IntII) 및 recombination site (attII)가 있으며, 3'-CS 보존지역은 소독제 내성 유전자(qacE $\Delta$ I) 및 sulfonamide 내성 sul1 유전자로 구성 되어 있었다. 5'-CS 및 3'-CS 보존지역 사이에 있는 variable region에서는 IMP-6 MBL 생성 유전자(blalMP-6), quaternary ammonium compound-resistance protein 생성 유전자(qac) cassette, aminoglycoside $6^{\prime}-\mathrm{N}$-acetyltransferase 생성 유전자 (aacA4) cassette, oxacillin계 항생제에 활성을 부여하는 broad-spectrum beta-lactamase OXA-1 생성 유전자(blaoxA-1) cassette 및 streptomycin과 spectinomycin에 내성을 부여하는 aminoglycoside adenyltransferase 생성 유전자(aadAI) cassette 등이 관찰되었다. 다섯 유전자 cassette 모두는 59 base element (59-be) recombination site를 지니고 있었다(Fig. 1).

ERIC PCR에 의한 IMP-6 및 VIM-2 생성 P. aeruginosa 의 역학적 연관성 분석

내성균주의 역학적 연관성 조사에서 band의 분자량과 개 수를 비교하여 두 개 이상의 band차이가 나면 역학적 상관 관계가 없는 것으로 판단하였다. IMP-6를 생성하는 8균주의 역학적 연관성을 확인하는 시험에서 다섯 균주 $(1,2,3,5,8$ 번)가 역학적 연관성이 있는 것으로 나타났다(Fig. 2). 또한 VIM-2를 생성하는 17 주 가운데 3 균주인 $(4,5,6$ 번)이 연관 성이 있고, $(11,12,13$ 번)이 서로 역학적 연관성이 있음이 확인되었다(Fig. 3). Fig. 4에서는 P. aeruginosa에서 분리한 IMP-6와 VIM-2를 나타낸 것으로 2,3번은 IMP-6 producing 이고 5,6번이 VIM-2 producing를 PCR banding pattern으로 나타낸 것이다.

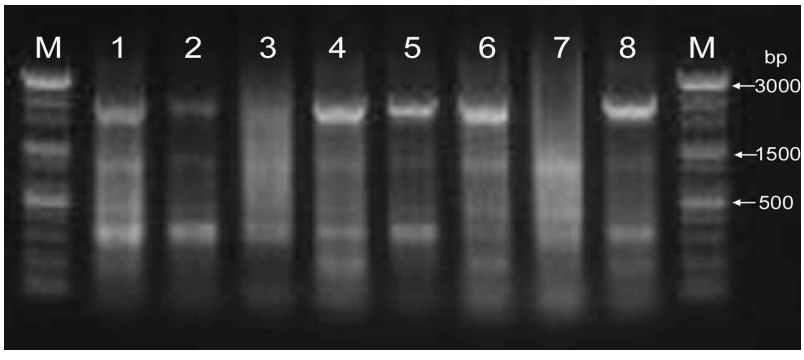

Fig. 2. Representative ERIC PCR banding patterns with ERIC 1 primer with clinical IMP-6-producing $P$. aeruginosa isolates from a university hospital, Busan, South Korea.

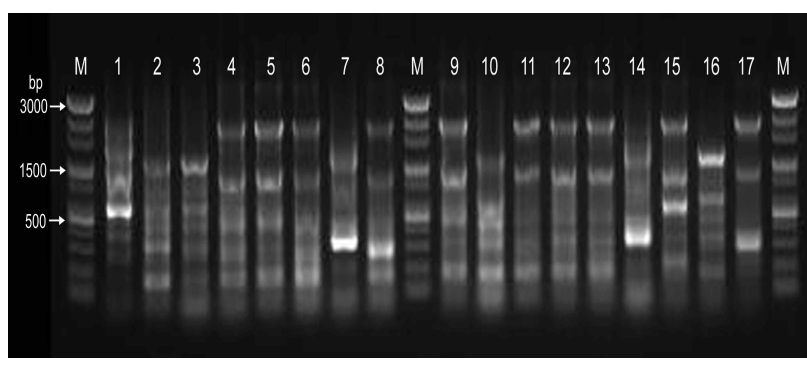

Fig. 3. Representative ERIC PCR banding patterns with ERIC 1 primer with clinical VIM-2-producing $P$. aeruginosa isolates from a university hospital, Busan, South Korea.

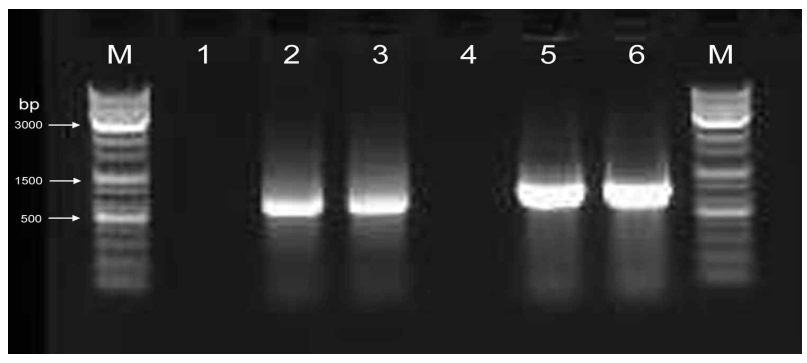

Fig. 4. PCR banding patterns of IMP-6 and VIM-2-producing $P$. aeruginosa isolates from a university hospital, Busan, South Korea. M: 100-bp plus ladder, lane 1: IMP-6 negative control, lane 2 and 3: IMP-6 positive strains, 4 : VIM-2 negative control, lane 5 and 6: VIM-2 positive strains 


\section{고 찰}

본 연구를 통해 분리된 imipenem 혹은 meropenem에 내성 을 갖는 $P$. aeruginosa 42 주는 cabapenem뿐만 아니라 cephalosporin계, aminoglycoside계 및 fluoroquinolone계 등에도 내성을 보이는 광범위 다약제 내성임을 확인할 수 있었다. Carbapenem계 항균제는 extended-spectrum $\beta$-lactamase, AmpC $\beta$-lactamase 등 그람 음성세균이 생성하는 $\beta$ -lactamase 대부분에 안정하며, 표적물 질인 penicillin-binding protein과의 친화도가 높아 peptidoglycan 세포벽 합성을 효 과적으로 억제한다. 그러나 최근 MBL 생성에 의해서 carbapenem에 대한 내성을 획득한 $P$. aeruginosa 등 그람 음성세균이 자주 보고되었는데, 2004년 전국 44여개 의료기관을 대상으로 조사한 Korean Nationwide Surveillance of Antimicrobial Resistance (KONSAR)의 보고에 의하면 imipenem 내성 $P$. aeruginosa가 $24.0 \%$ 로써 carbapenem 내성 P. aeruginosa가 흔 함을 알 수 있었다[9].

본 연구에서는 cabapenemase 및 MBL 생성균주의 선별을 위하여 Hodge 변법 및 EDST법을 사용하였는데, Hodge 변법 은 MBL 생성균주 뿐 아니라 비금속성 carbapenemase를 생성 하는 균주도 이 시험에서 양성반응을 보였으며, EDST 시험은 $\mathrm{MBL}$ 의 활성이 $\mathrm{EDTA}$ 에 의해서 억제되는 원리를 이용한 검사 법으로 이 효소를 생성하는 균주의 선별에 사용하였다[8]. 본 연구에서 28 주 $(66.7 \%)$ 가 Hodge 시험에 양성반응을 보였고, 23 주(54.8\%)가 EDST 시험에 양성반응을 보여 이들 세균의 MBL 생성을 추측할 수 있었다. 그래서 blaMBL을 검출하기 위 해 primer를 염기서열 상동성에 따라 class B의 IMP형과 VIM 형 $\mathrm{MBL}$ 를 각각 6개 및 2 개의 group과 최근 보고된 class $\mathrm{B}$ 의 GIM-1, SPM-1과 SIM-1의 primer를 사용하여 PCR 및 sequencing을 실시하였다. 본 연구의 대상이 된 $P$. aeruginosa 42 주 중 17 주가 primer VIM-2F, VIM-2R의 PCR에서 양성반응 을 보였고, PCR 산물의 염기서열 분석결과 모두 VIM-2로 확 인되었다. 또한 8 주가 IMP-1의 아형을 검출하기 위한 primer IMP-1F, IMP-1R의 PCR에서 양성반응을 보였고, 염기서열 분 석결과 모두 IMP-6로 확인되었다. IMP-6은 일본에서 분리된 P. aeruginosa에서 처음 보고되었으며, 이 유전자의 특징은 imipenem에 활성이 강한 blamp-1 유전자의 196번 serine이 glycine으로 치환되어 meropenem에 강력한 활성을 갖고 있 다[19]. 국내에서는 류 등[14]이 대구지역에서 이 유전자를 보 유한 P. aeruginosa에 의한 집단발병을 보고하였으며, 용 등[20] 은 2003년에서 2004년 동안 수집된 imipenem 내성 MBL 생성 P. aeruginosa의 유전형을 분석하여 2003년 bla (6.6\%), 2004년 bla $(0.6 \%)$ 였음을 보고하였다. 이러한 결과는 본 실험에서 분리한 유전자 유형과 같으므로 대구에서 부산으로의 지역적 확산이 의심되며, 지역사회 토착화뿐만 아니라 전국으로 확산될 가능
성도 있어 추후 전국적인 연구가 필요할 것으로 생각된다.

본 연구에서 분리된 blaMP- 6 유전자는 다른 내성 유전자 cassette와 함께 class 1 integron에 포함되어 있었다. 이 유전자의 상류에는 intI1 유전자가 있어 이 유전자가 가장 나중에 획득 되어진 것으로 추측된다. blaMP-6 유전자 하류에는 qac-aacA4-blaxxA-1-aadA1 유전자가 3'CS 전까지 배열되어 있었 으며, 이 배열은 대구지역에서 이 유전자에 의한 발병이 보고 된 유전자의 gene cassette와 일치하는 것을 확인하였다 (GenBank accession no. EU117233)(Fig. 4). 따라서 이들 integron을 획득한 세균은 $\beta$-lactam 항균제뿐 아니라 다른 계열 의 항균제에 대한 내성도 동시에 획득하여 더욱 위협적이며, 전달성이 높기 때문에 클론확산뿐만 아니라 수평 확산에 의해 서도 내성이 전달될 수 있다. IMP-6와 VIM-2를 생성하는 25 주 를 제외한 17 주는 본 연구에서 사용된 primer로는 검출할 수 없어서 향후 새로운 primer를 고안하는 등 추가적인 연구가 필요할 것으로 생각된다.

IMP-6를 생성하는 $P$. aeruginosa 8주에 대한 MIC 범위는

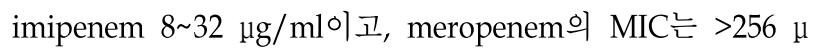
$\mathrm{g} / \mathrm{ml}$ 이었다. 이는 IMP-6를 생성하는 세균이 강력한 meropenemase를 생성하고 있음이 확인된 것이다. 또한 VIM-2를 생성하는 균의 MIC 범위는 imipenem과 meropenem 모두 $32 \sim 128 \mu \mathrm{g} / \mathrm{ml}$ 이어서 전형적인 $\mathrm{MBL}$ 의 양상을 띠고 있음이 확인되었으나 이들 내성 유전자의 접합에 의한 전달 실험에서 는 내성전달 양상을 보인 균주는 나타나지 않았다. 그러나 MBL유전자는 integron에 존재하여 transposon 또는 plasmid 를 이용하여 다른 균에 쉽게 전달될 수 있으므로 내성확산을 막는 연구가 계속 되어야 할 것으로 생각된다.

ERIC PCR의 결과 각 유전자를 생성하는 세균들의 일부에 서는 집단발병이 있었음이 확인되었고, 일부는 다른 밴드양상 을 보여 대상병원에서 IMP-6와 VIM-2를 생성하는 P. aeruginosa가 토착화되어 집단발병을 일으키는 등 문제를 야기 시킬 것으로 우려된다. 따라서 이들을 보유한 세균이 지역사회에 정착하면 세균에 의한 감염증 치료 시 치료 약제를 선택하는 데 어려움이 증가될 것이므로 지속적인 감시와 이들 유전자를 보유한 내성균의 확산을 막는 추가적인 연구가 필요하다고 생각한다.

\section{감사의 글}

이 논문을 내기까지 도움을 주신 배일권 선생님과 박인달 교수님께 감사의 글을 전합니다.

\section{References}

1. Bermudes, H., Jude, F., Chaibi, E. B., Arpin, C., Bebear, C., Labia, R. and Quentin, C. 1999. Molecular characterization 
of TEM-59 (IRT-17), a novel inhibitor-resistant TEM-derived B-lactamase in a clinical isolate of Klebsiella oxytoca. Antimicrob. Agents Chemother. 43, 1657-1661.

2. Bonfiglio, G., Laksai, Y., Granchino, L., Amicosante, G., and Nicoletti, G. 1998. Mechanisms of $\beta$-lactam resistance amongst Pseudomonas aeruginosa isolated in an Italian survey. J. Antimicrob. Chemother. 42, 697-702.

3. Castanheira, M., Toleman, M. A., Jones, R. N., Schmidt, F. J. and Walsh, T. R. 2004. Molecular characterization of a B-lactamase gene, blacim-1, encoding a new subclass of metallo-B-lactamase. Antimicrob. Agents Chemother. 48, 4654-4661.

4. Chen, H. Y., Yuan, M. and Livermore, D. M. 1995. Mechanisms of resistance to $\beta$-lactam antibiotics amongst Pseudomonas aeruginosa isolates collected in the UK in 1993. J. Med Microbiol. 43, 300-309.

5. Cohen, J. and Powerly, W. G. 2004. Pseudomonas and miscellaneous gram-negative bacilli. Infections Diseases, 2nd ed, New York, Mosby, 2203-2226.

6. Lau, Y. J., Liu, P. Y., Hu, B. S., Shyr, J. M., Shi, Z. Y., Tsai, W. S., Lin, Y. H. and Tseng, C. Y. 1995. DNA fingerprinting of Pseudomonas aeruginosa serotype $\mathrm{O} 11$ by enterobacterial repetitive intergenic consensus-polymerase chain reaction and pulsed-field gel electrophoresis. J. Hosp. Infect. 31, 61-66.

7. Lee, K., Chong, Y., Shin, H. B., Kim, Y. A., Yong, D. and Yum, J. H. 2001. Modified Hodge test and EDTA-disk synergy tests to screen metallo- $\beta$-lactamase-producing strains of Pseudomonas and Acinetobacter species. Clin. Microbiol. Infect. 7, 88-91.

8. Lee, K., Lim, J. B., Yum, J. H., Yong, D., Chong, Y., Kim, J. M. and Livermore, D. M. 2002. blaviM-2 cassette-containing novel integrons in metallo- $\beta$-lactamase- producing Pseudomonas aeruginosa and Pseudomonas putida isolates disseminated in Korean hospital. Antimicrob. Agents Chemother. 46, 1053-1058.

9. Lee, K., Park, A. J., Kim, M. Y., Lee, H. J., Cho, J. H., Kang, J. O., Yong, D., Chong, Y. and KONSAR group. 2009. Metallo- $\beta$-lactamase-producing Pseudomonas spp. in Korea: high prevalence of isolates with VIM-2 type and emergence of isolates with IMP-1 type. J. Yonsei Med 50, 335-339.

10. Lee, K., Yum, J. H., Yong, D., Lee, H. M., Kim, H. D., Docquier, J. D., Rossolini, G. M. and Chong, Y. 2005. Novel acquired metallo- $\beta$-lactamase gene, blasIM-1, in a class 1 integron from Acinetobacter baumannii clinical isolates from Korea. Antimicrob. Agents Chemother. 49, 4485-4491.

11. Livermore, D. M. 1992. Interplay of impermeability and chromosomal $\beta$-lactamase activity in imipenem-resistant Pseudomonas aeruginosa. Antimicrob. Agents Chemother. 36, 2046-2048.

12. Poirel, L., Magalhaes, M., Lopes, M. and Nordmann, P. 2004.
Molecular analysis of metallo- $\beta$-lactamase gene blaspM-1-surrounding sequences from disseminated Pseudomonas aeruginosa isolates in Recife, Brazil. Antimicrob. Agents Chemother. 48, 1406-1409.

13. Queenan, A. M. and Bush, K. 2007. Carbapenemases: the versatile $\beta$-lactamases. Clin. Microbiol. Rev. 20, 440-458.

14. Ryoo, N. H., Lee, K., Lim, J. B., Lee, Y. H., Bae, I. K. and Jeong, S. H. 2009. Outbreak by meropenem-resistant Pseudomonas aeruginosa producing IMP-6 metallo- $\beta$-lactamase in a Korean hospital. Diagn. Microbiol. Infect Dis. 63, 115-117.

15. Sanger, F., Nicklen, S. and Coulson, A. R. 1977. DNA sequencing with chain-terminating inhibitors. Proc. Natl. Acad Sci. USA. 74, 5463-5467.

16. Satake, S., Yoshihara, E. and Nakae, T. 1990. Diffusion of B-lactam antibiotics through liposome membranes reconstituted from purified porins of the outer membrane of Pseudomonas aeruginosa. Antimicrob. Agents Chemother. 34, 685-690.

17. Watanabe, M., Lyobe, S., Inoue, M. and Mitsuhashi, S. 1991. Transferable imipenem resistance in Pseudomonas aeruginosa. Antimicrob. Agents Chemother. 35, 147-151.

18. Wayne, P. A. 2008. Performance standards for antimicrobial susceptibility testing. Clinical and Loboratory Standards Institute 18th ed, M100-S18.

19. Yano, H., Kuga, A., Okamoto, R., Kitasato, H., Kobayashi, T. and Inoue, M. 2001. Plasmid-encoded metallo- $\beta$ -lactamase (IMP-6) conferring resistance to carbapenems, especially meropenem. Antimicrob. Agents Chemother. 45, 1343-1348.

20. Yong, D., Choi, Y. S., Roh, K. H. and Kim, C. K. 2006. Increasing Prevalence and Diversity of Metallo- $\beta$-lactamases in Pseudomonas spp., Acinetobacter spp. from Korea. Antimicrob. Agents Chemother. 50, 1884-1886.

21. Yum, J. H., Yi, K., Lee, H., Yong, D., Lee, K., Kim, J. M., Rossolini, G. M. and Chong, Y. 2002. Molecular characterization of metallo- $\beta$-lactamase-producing Acinetobacter baumannii and Acinetobacter genomospecies 3 from Korea: identification of two new integrons carrying the bla IIM-2 $_{\text {I }}$ gene cassettes. J. Antimicrob. Chemother. 42, 217-219.

22. Yum, J. H., Yong, D., Lee, K., Kim, H. S. and Chong, Y. 2004. A new intergron carrying VIM-2 metallo- $\beta$-lactamase gene cassette in a Serratia marcescens isolates. Diagn. Microbiol. Infect Dis. 42, 217-219.

23. Ziha-Zarifi, I., Llanes, C., Köhler, T., Pechere, J. C. and Plesiat, P. 1999. In vivo emergence of multidrug-resistant mutants of Pseudomonas aeruginosa overexpressing the active efflux system MexA-MexB-OprM. Antimicrob. Agents Chemother. 43, 287-291. 
초록 : 임상에서 분리된 Metallo- $\beta$-lactamase 생성 Pseudomonas aeruginosa의 분자역학

최명원*

(고신대학교 복음병원 항생제 내성 연구소)

사람의 감염증 치료에 사용되는 carbapenem계 약제에 대한 내성균의 출현 및 확산은 감염증 치료를 제한할 뿐만 아니라 집단 발병의 원인이 될 수 있다. 이에 본 연구에서는 $\beta$-lactam 약제에 내성을 갖는 Pseudomonas aeruginosa ( $P$. aeruginosa)를 대상으로 metallo-beta-lactamase (MBL)의 유전형을 규명함으로써 내성세균의 감염증 치 료지침 및 확산방지책 마련에 기초 자료를 제공하고자 하였다. 본 연구의 대상이 된 254 개의 임상 검체 중에서 42 주의 P. aeruginosa 를 분리하여 imipenem 혹은 meropenem에 내성을 나타내는 Hodge 변법과 EDST에서 각각 28 주와 23주가 양성반응을 보였다. DNA의 염기서열 분석결과 bla $a_{\mathrm{IMP}-6}$ 유전자 보유균이 8 주, bla $\mathrm{avIM}_{2}$ 유전자 보유 균이 17 주로 $59.5 \%(25 / 42)$ 가 $\mathrm{MBL}$ 을 생성하는 것으로 나타났다. blaMP- 6 의 유전자 환경은 blamp-6-qac-aacA4blaoxA-1-aadA1 유전자 배열을 지니고 있었다. 또한 ERIC PCR 결과 IMP-6과 VIM-2를 생성하는 일부 균주에서 역학적 연관성이 있음이 확인되었다. 본 연구에서 분리한 carbapenem계 항균제 내성 $P$. aeruginosa가 보유한 blaMP-6 유전자는 대구지역에서 발병이 보고된 유전자의 gene cassette와 일치하는 것으로 확인되었다. 따라서 이 들 세균이 지역사회에 정착하고 있고 이들을 보유한 세균에 의한 감염증 치료시 치료약제에 대한 선택압을 증가 시킬 것으로 우려된다. 그러므로 항균제 내성 검사를 통하여 적절한 항균제를 선택하고, 항균제 내성균들의 출현 과 확산을 막는 연구가 계속되어야 할 것으로 생각된다. 